\title{
Resolving the age \\ controversy of Pleistocene shoreline deposits in the Lower Coastal Plain in \\ northeastern South Carolina Zhixiong Shen
}

Department of Marine Science

Coastal Carolina University

Collaborators:

Eric Wright, Coastal Carolina Univeristy

Benjamin Loh, Coastal Carolina University Barbara Mauz, University of Liverpool

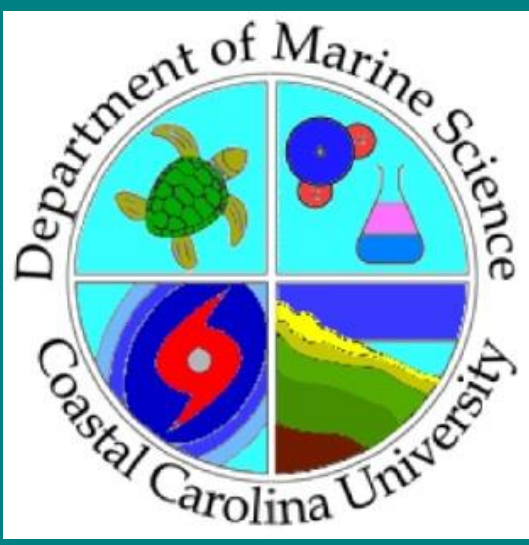




\section{Lower US Atlantic Coastal Plain}

- Pleistocene interglacial deposits driven by sea level change

- Key for studying interglacial sea level and climate changes

- Constraining ice sheet dynamics of glacial

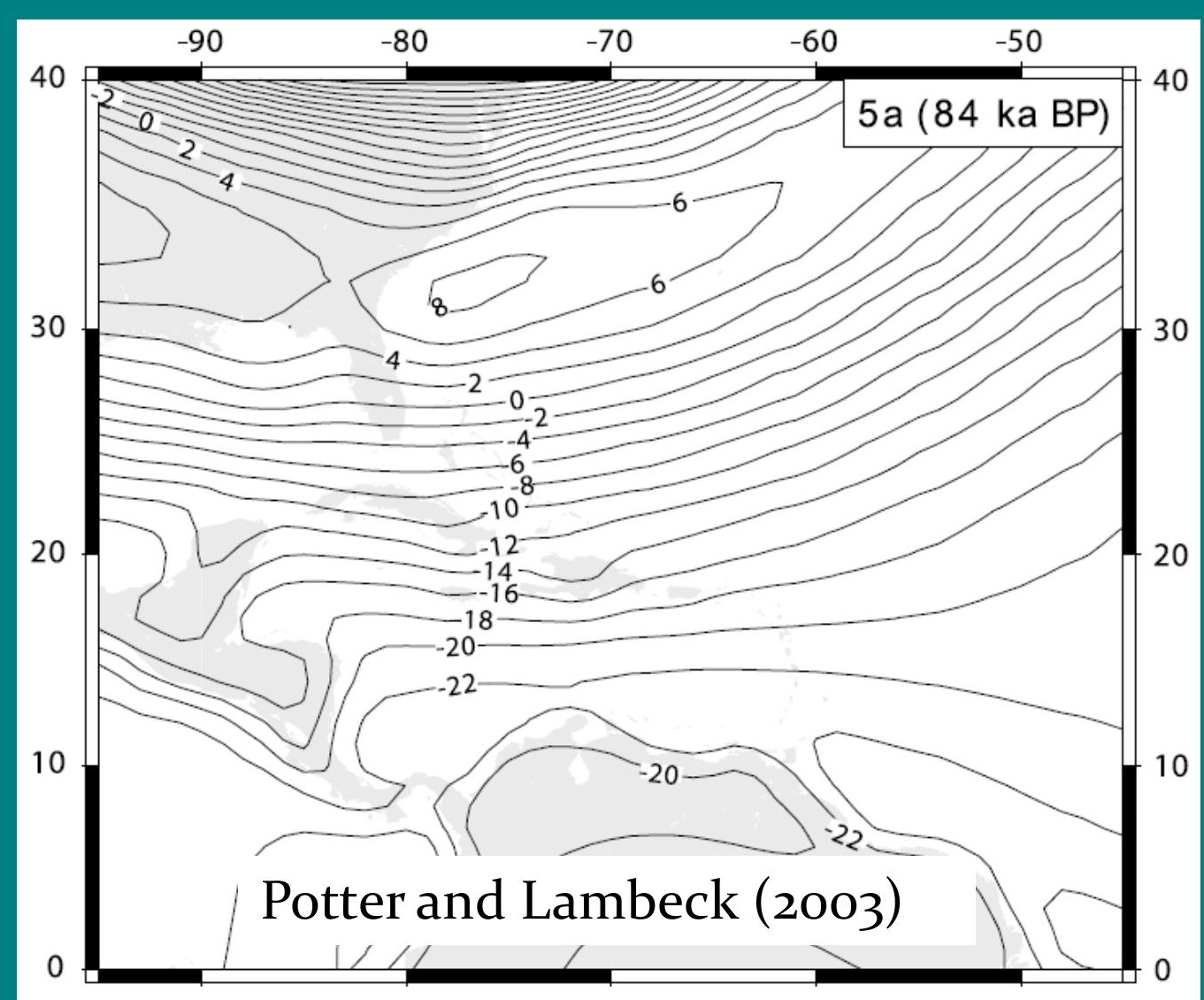




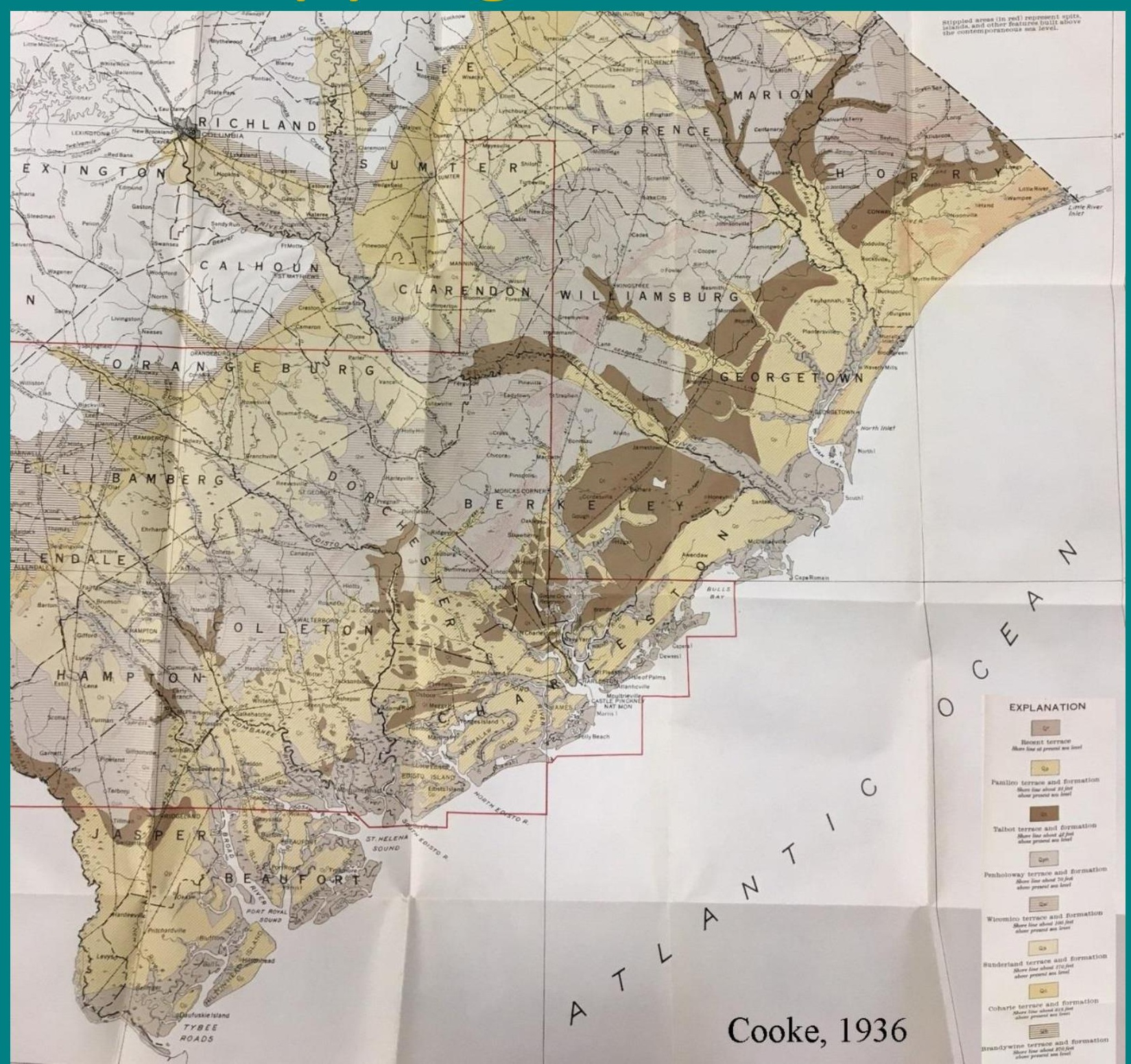




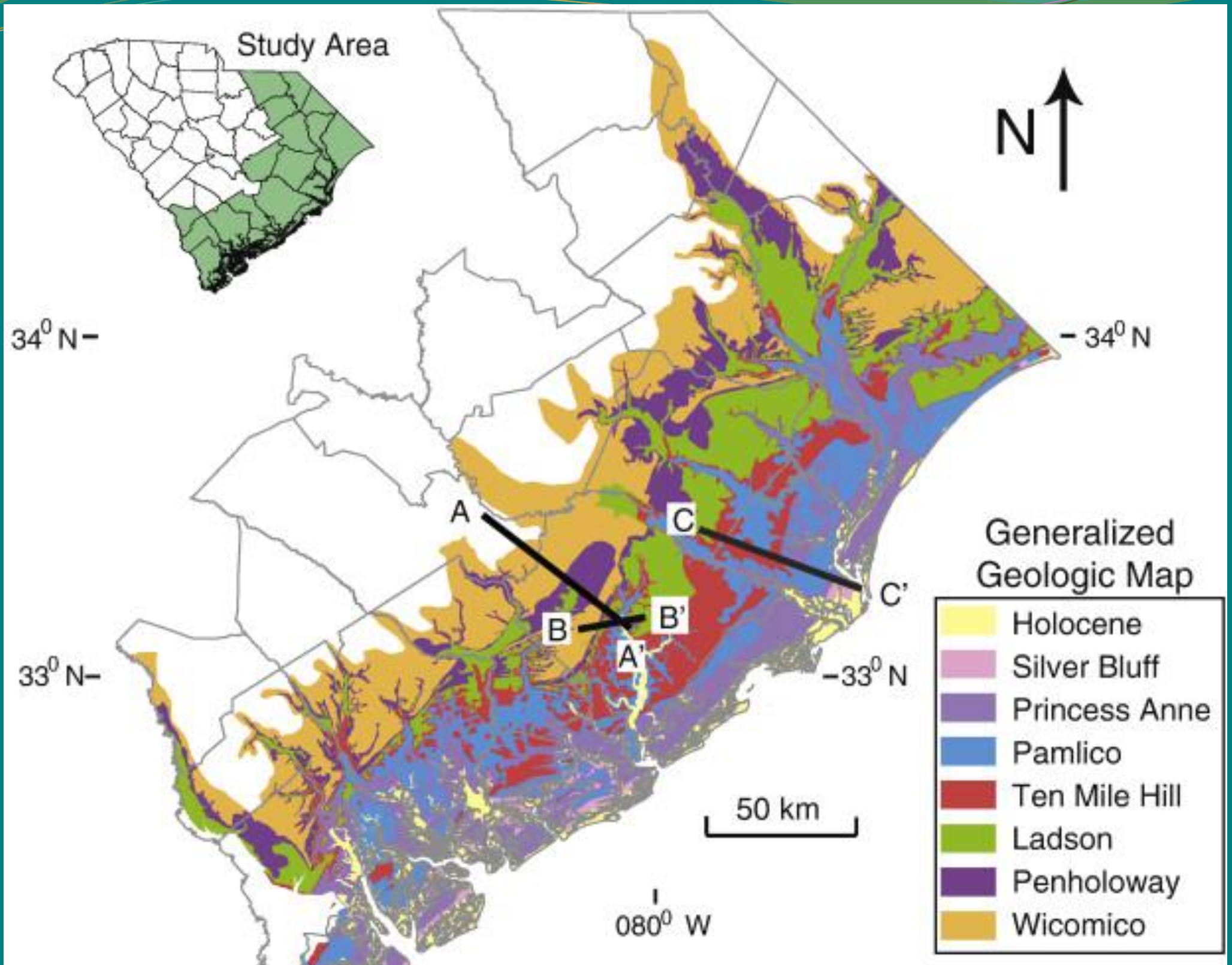

Modified from Doar and Willoughby, 2006 


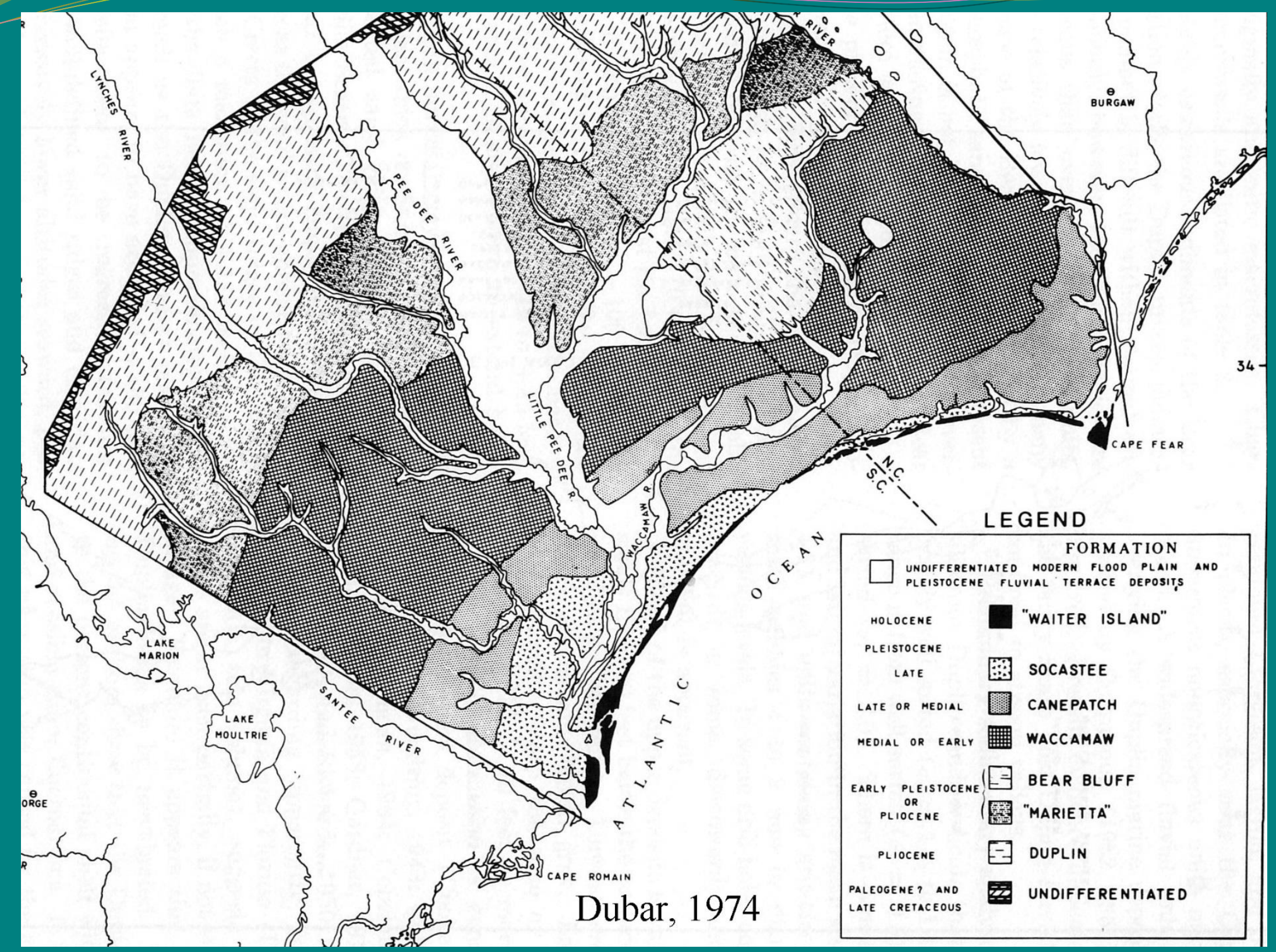




\section{Chronology Controversy}

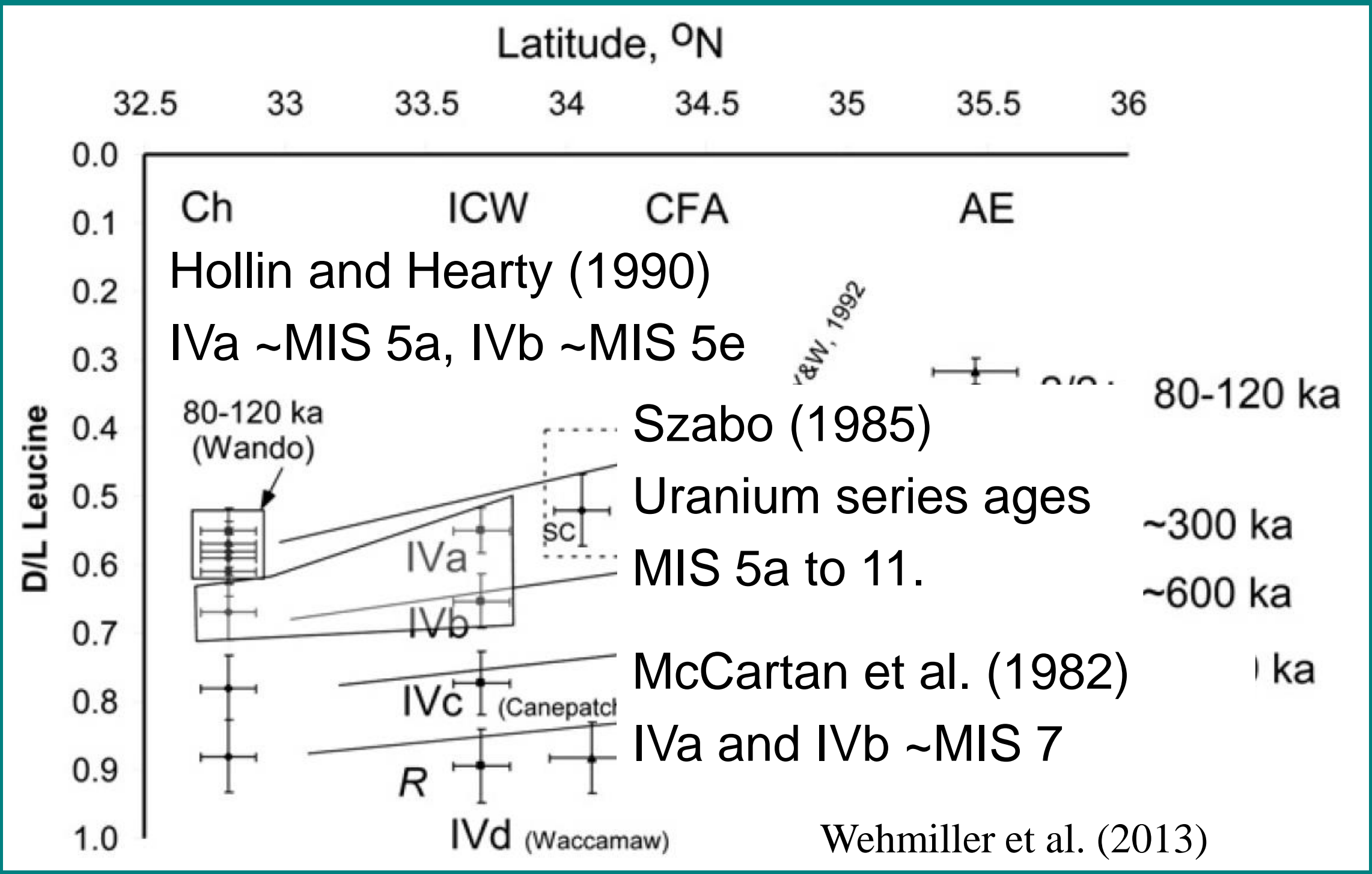


Methods

- Vibracore, Powerprobe core, and auger cores

- GPR

- OSL dating

- Myrtle Beach Airport

- Hobcaw Barony

- North Santee

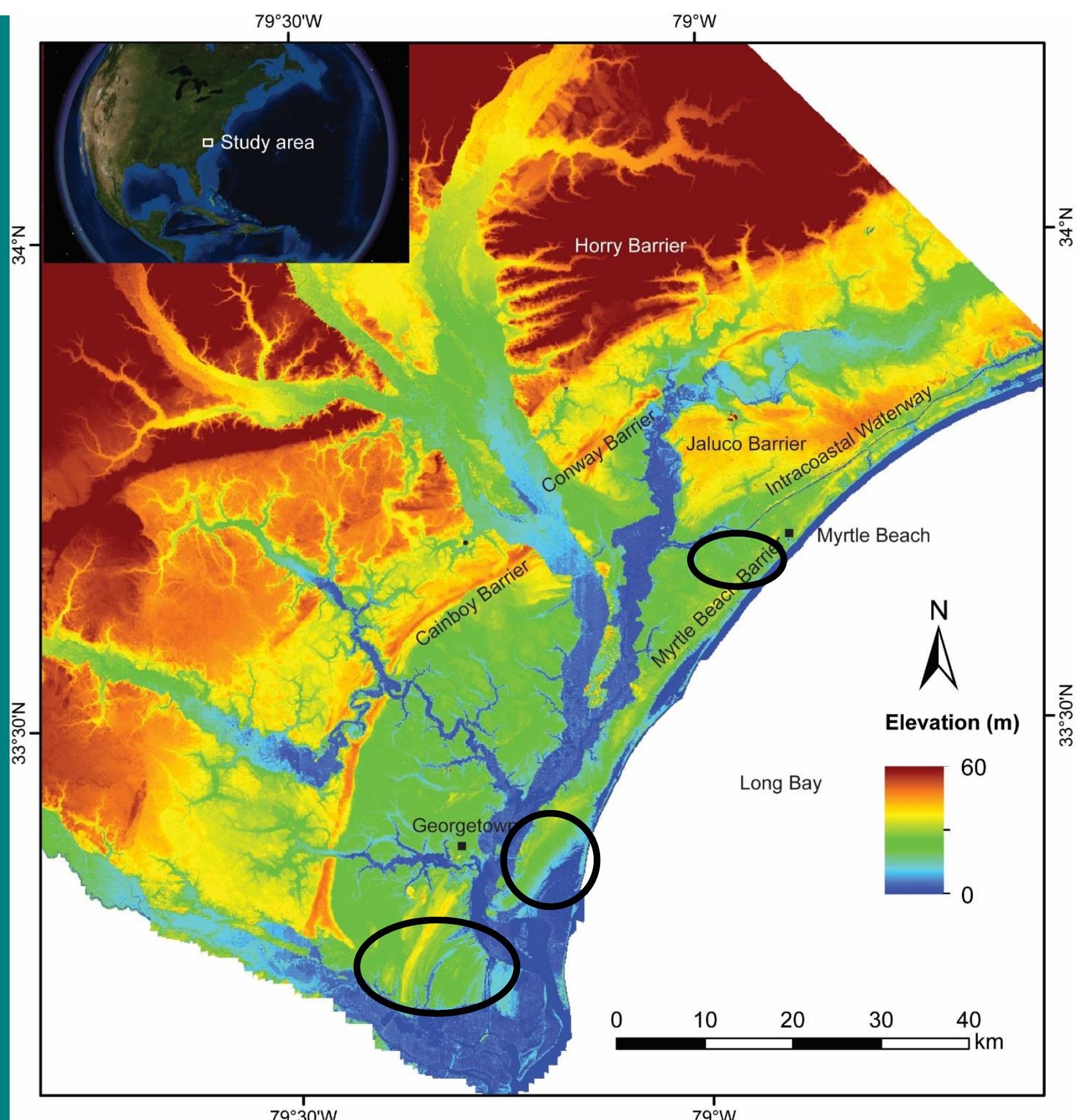


2017 GSA Southeastern Section Meeting

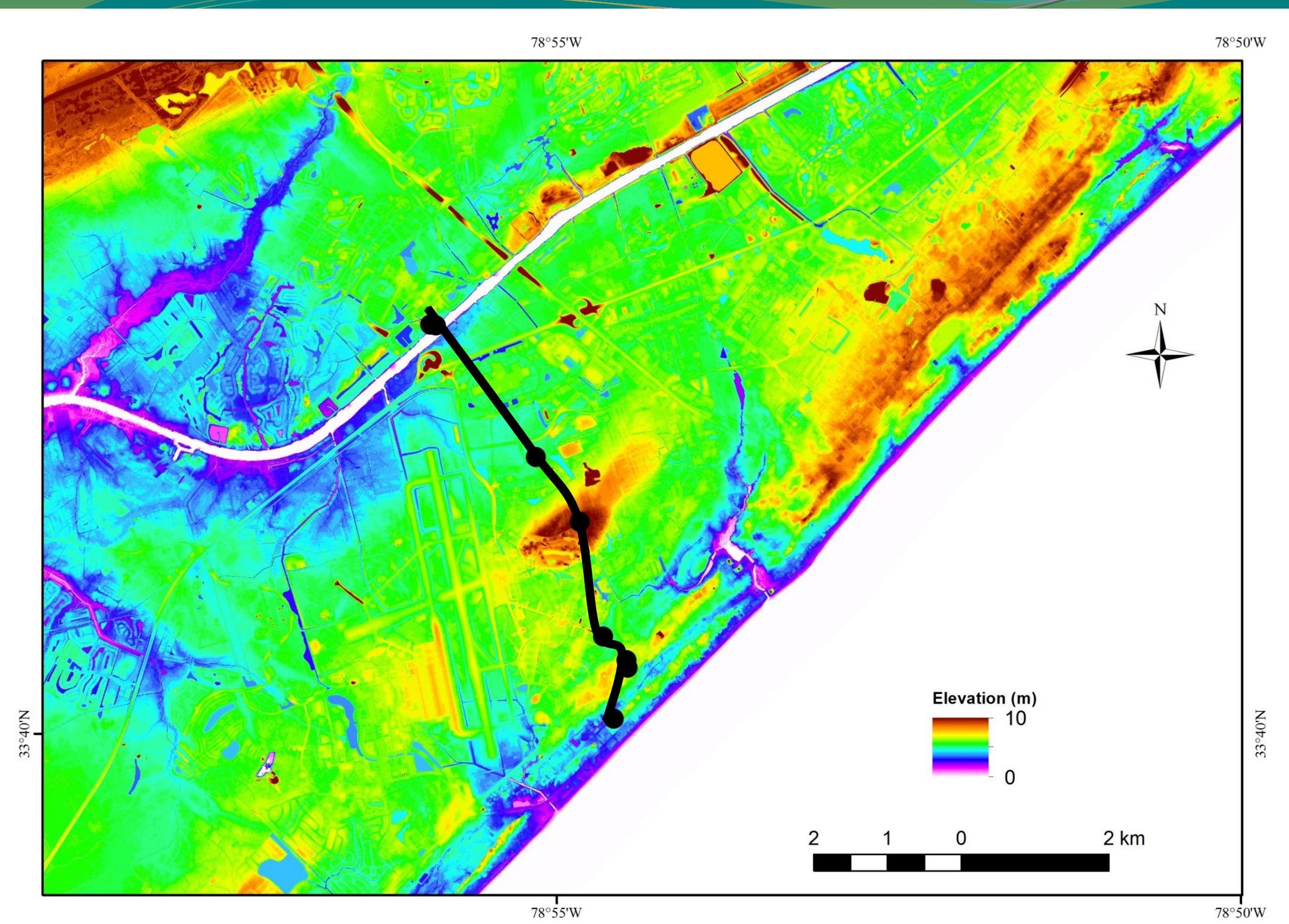


ICW at $1.3 \mathrm{~km}$ South of 501 Bridge
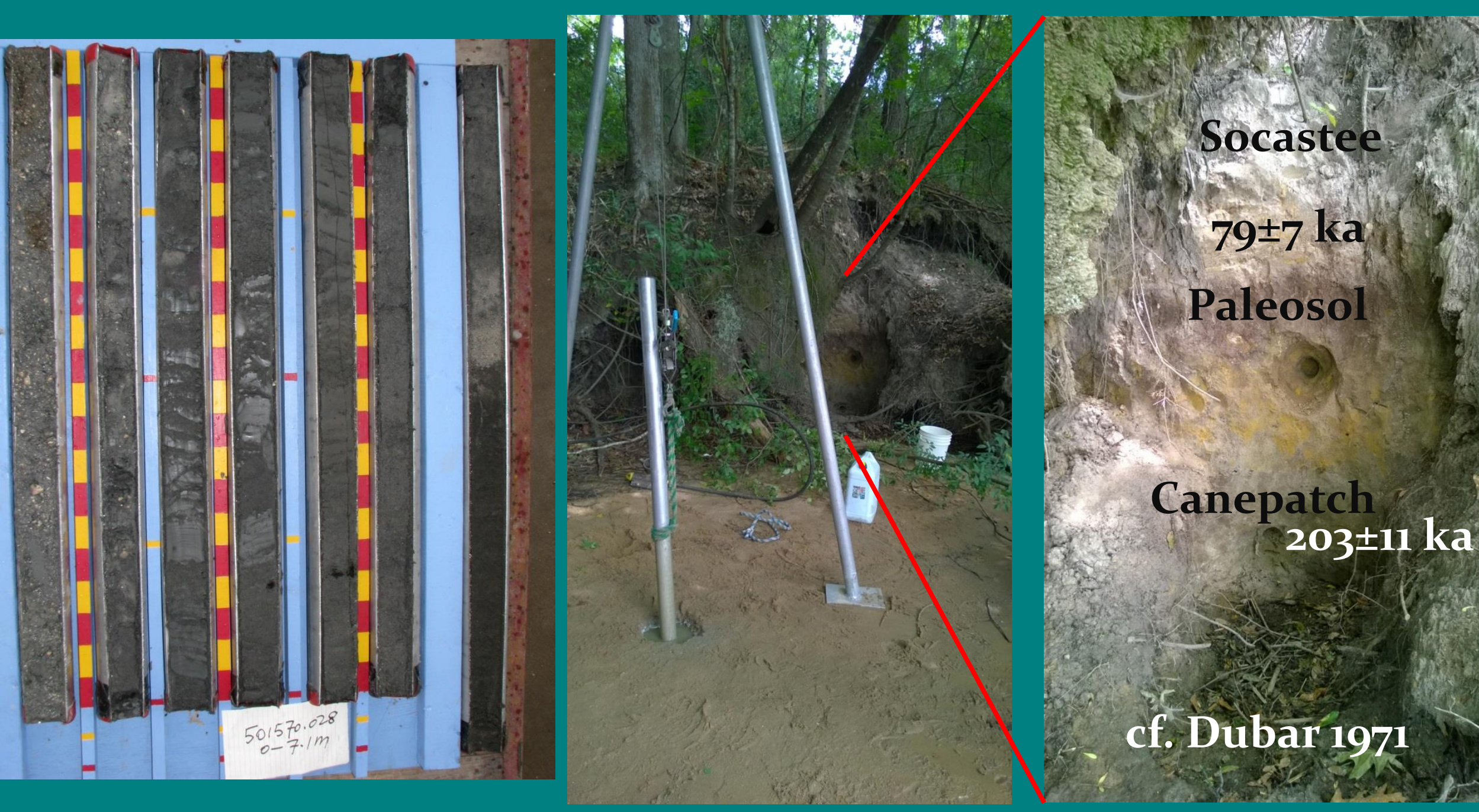


\section{Myrtle Beach Airport Cross Section}

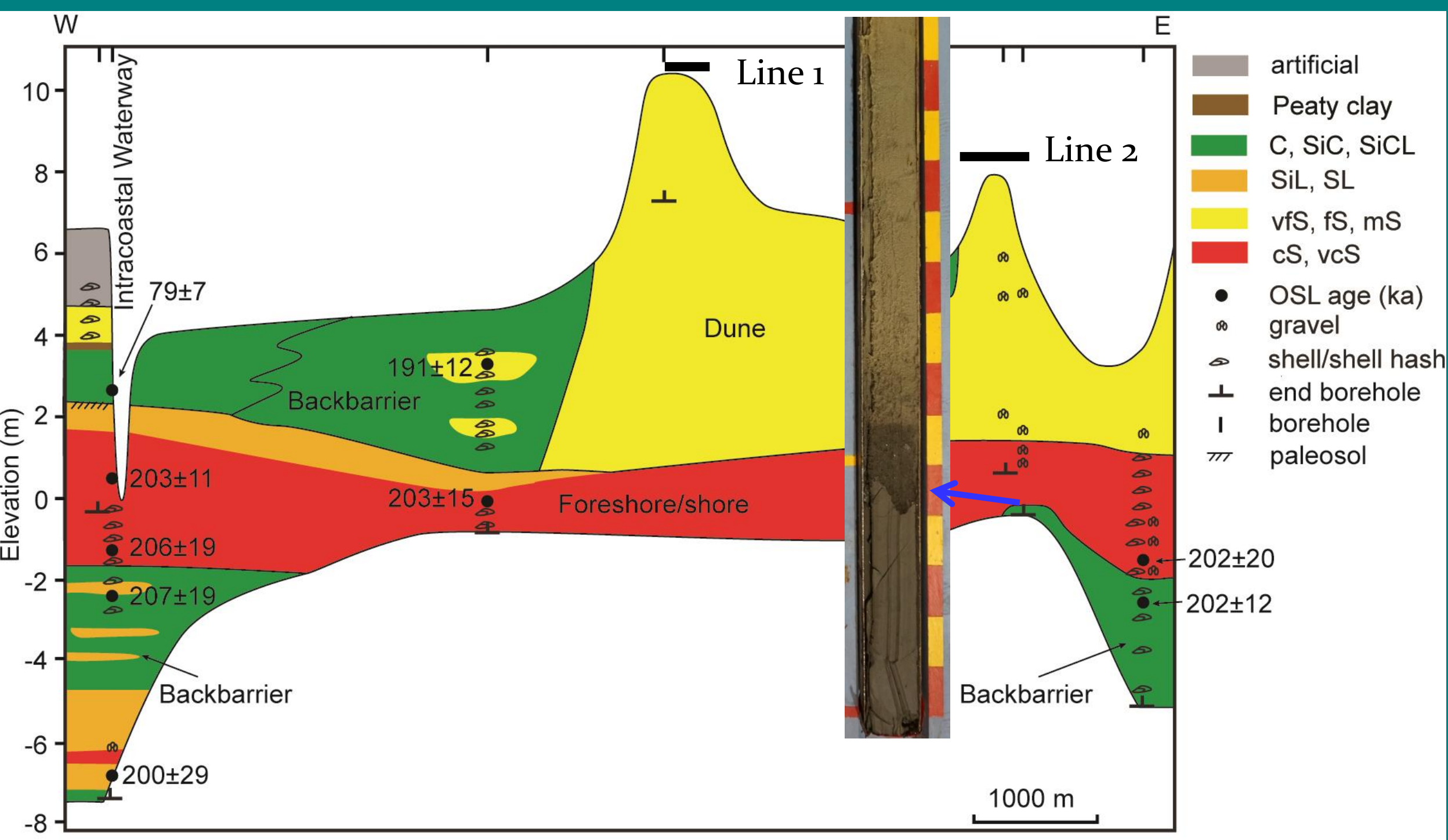




\section{Myrtle Beach Airport GPR}
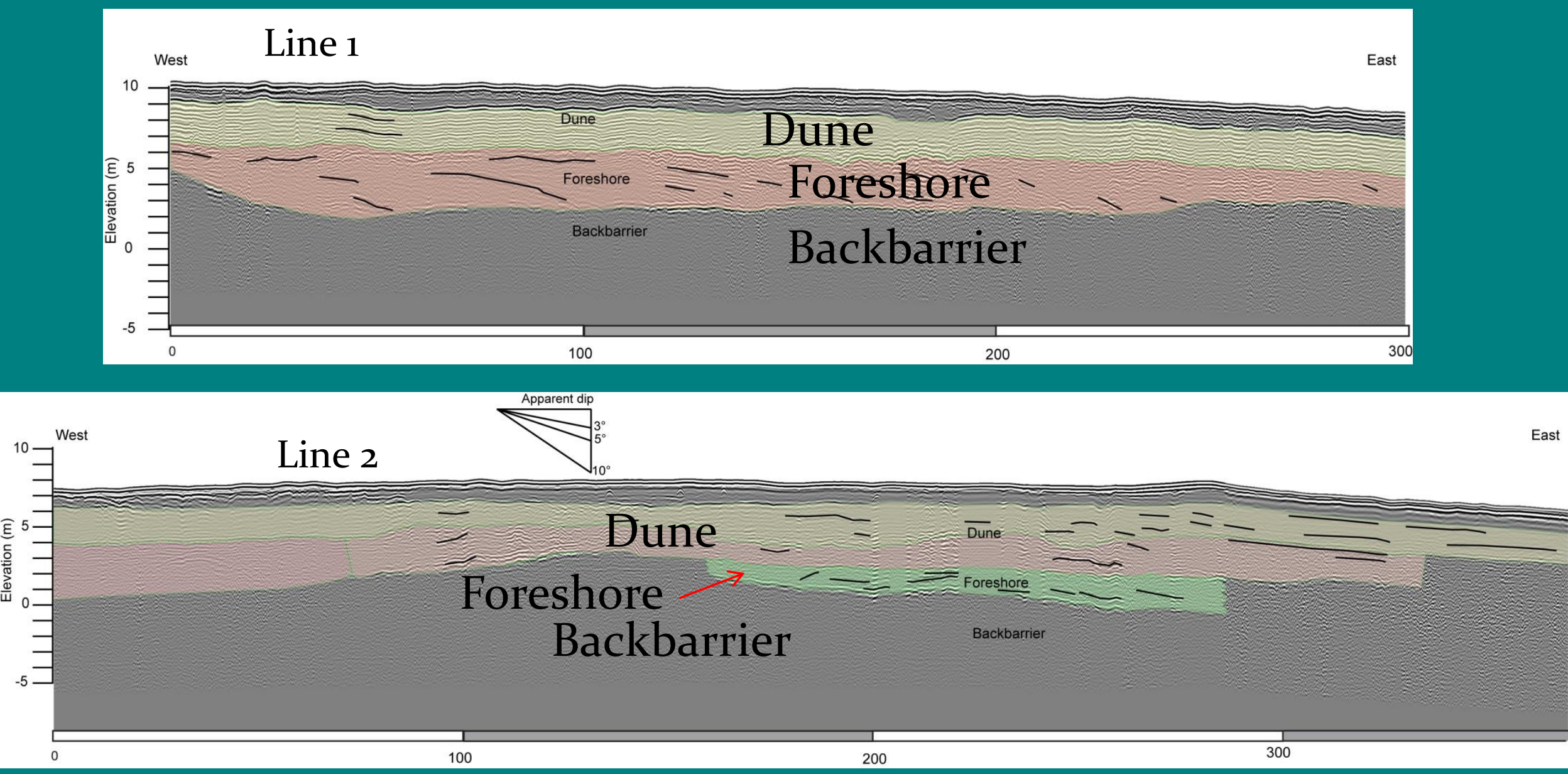


\section{lobcaw Barony Cross Section}
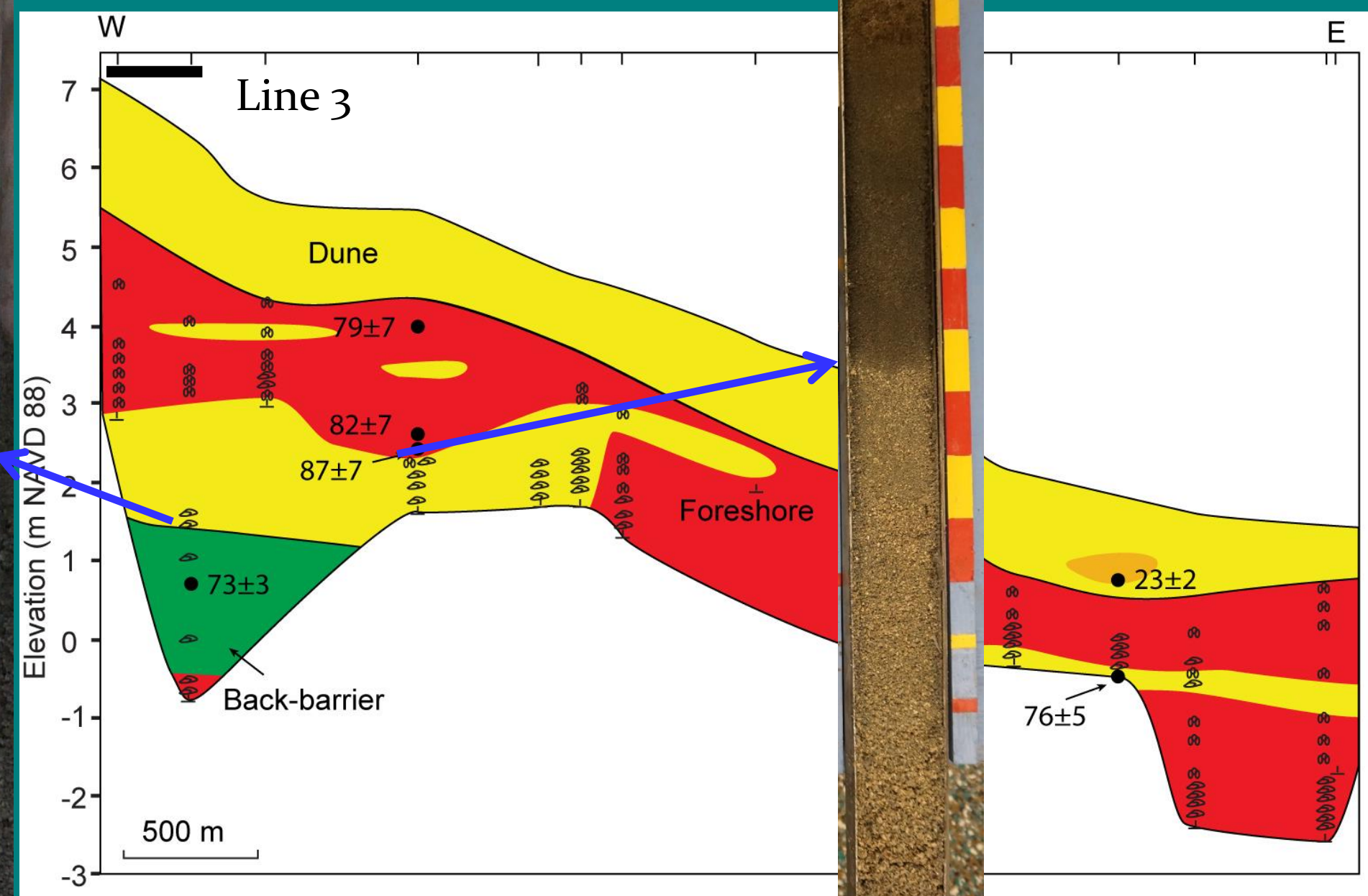

C, SiC, SiCL

SiL, SL

vfS, fS, mS

$\mathrm{cS}, \mathrm{vcS}$

- $\quad$ OSL age (ka)

- gravel

- shell/shell has

$\perp \quad$ end borehole

I borehole

mit paleosol 


\section{GSA Southeastern Section Meeting}

\section{Hobcaw Barony GPR}

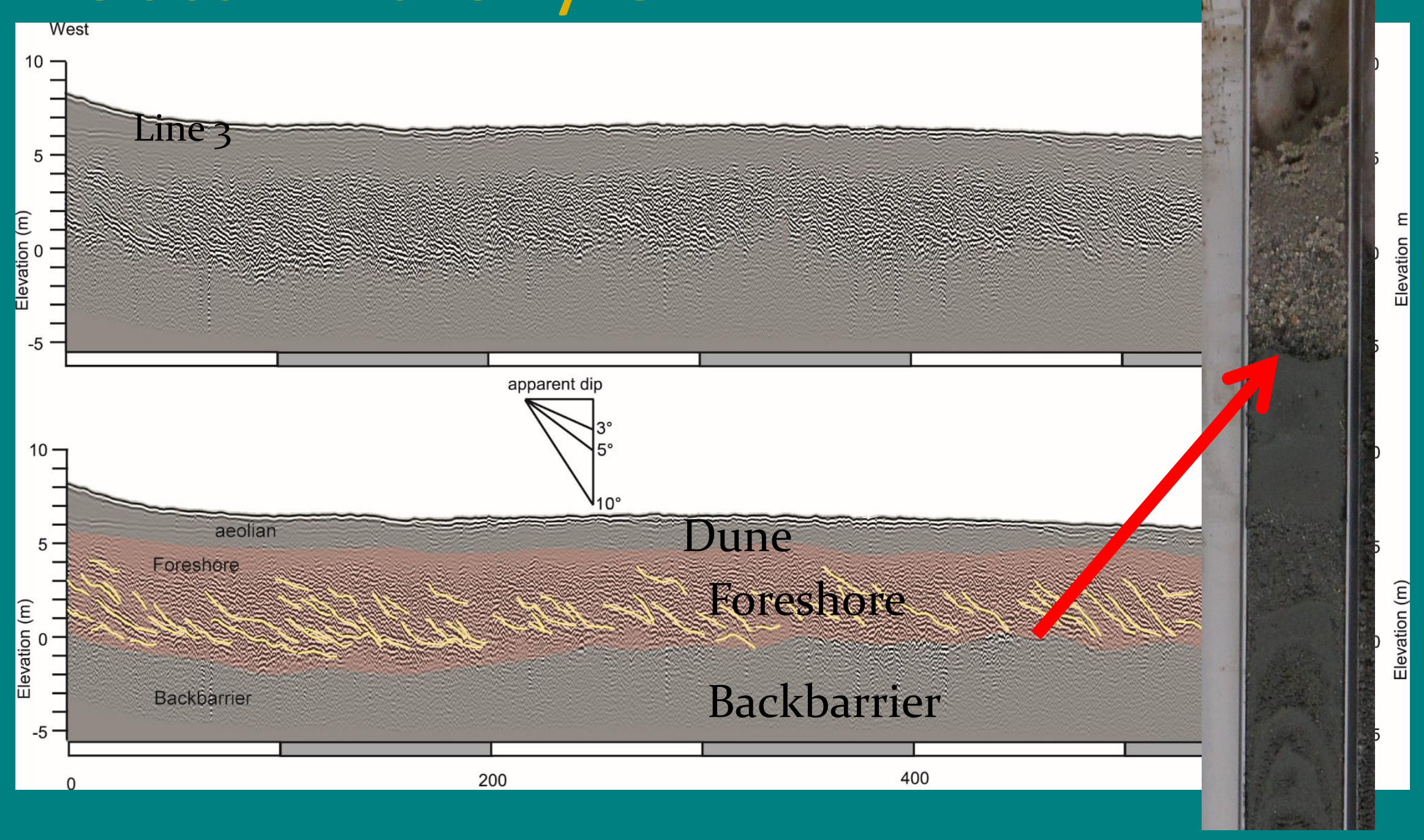




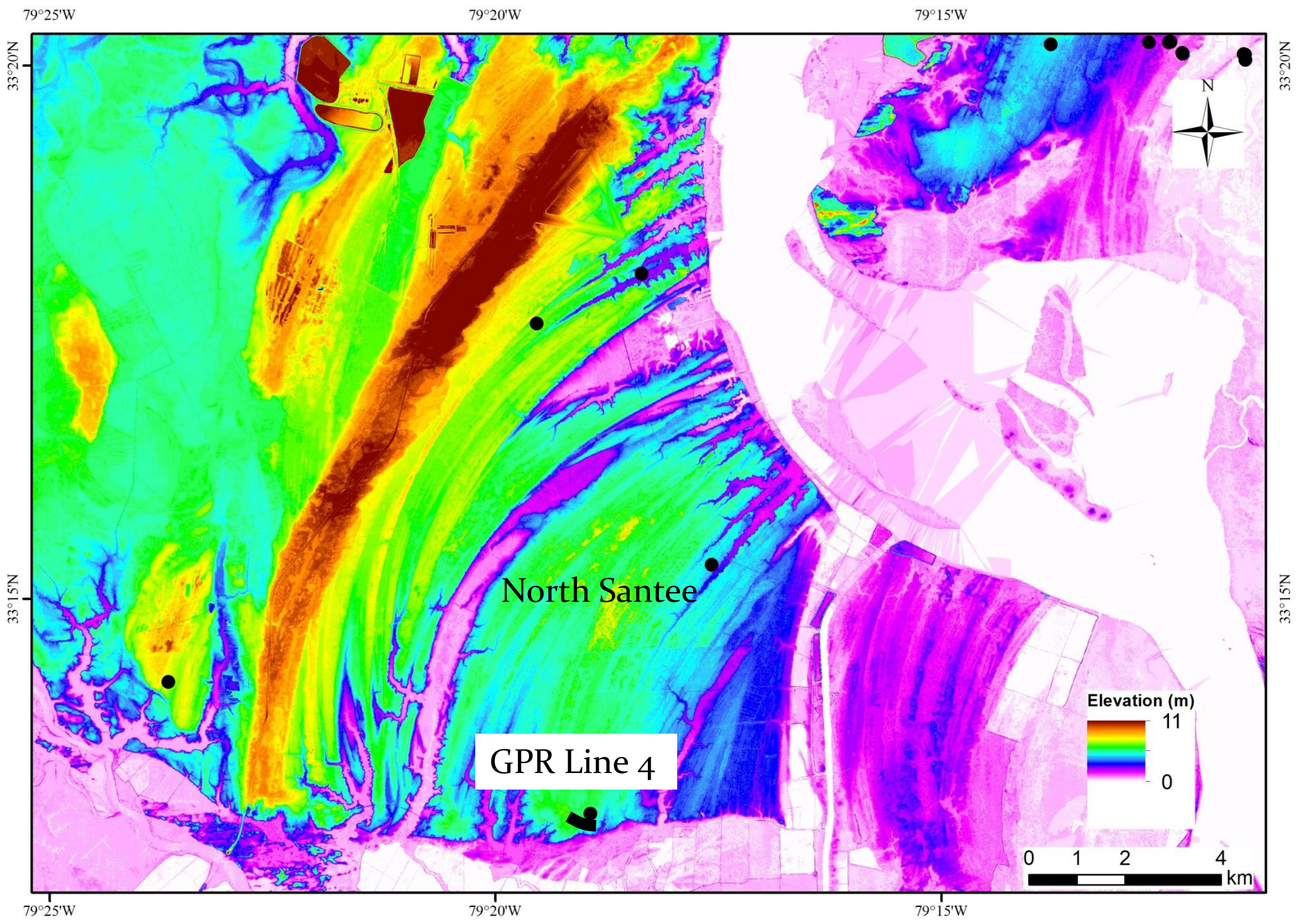




\section{North Santee GPR and Stratigraphy}
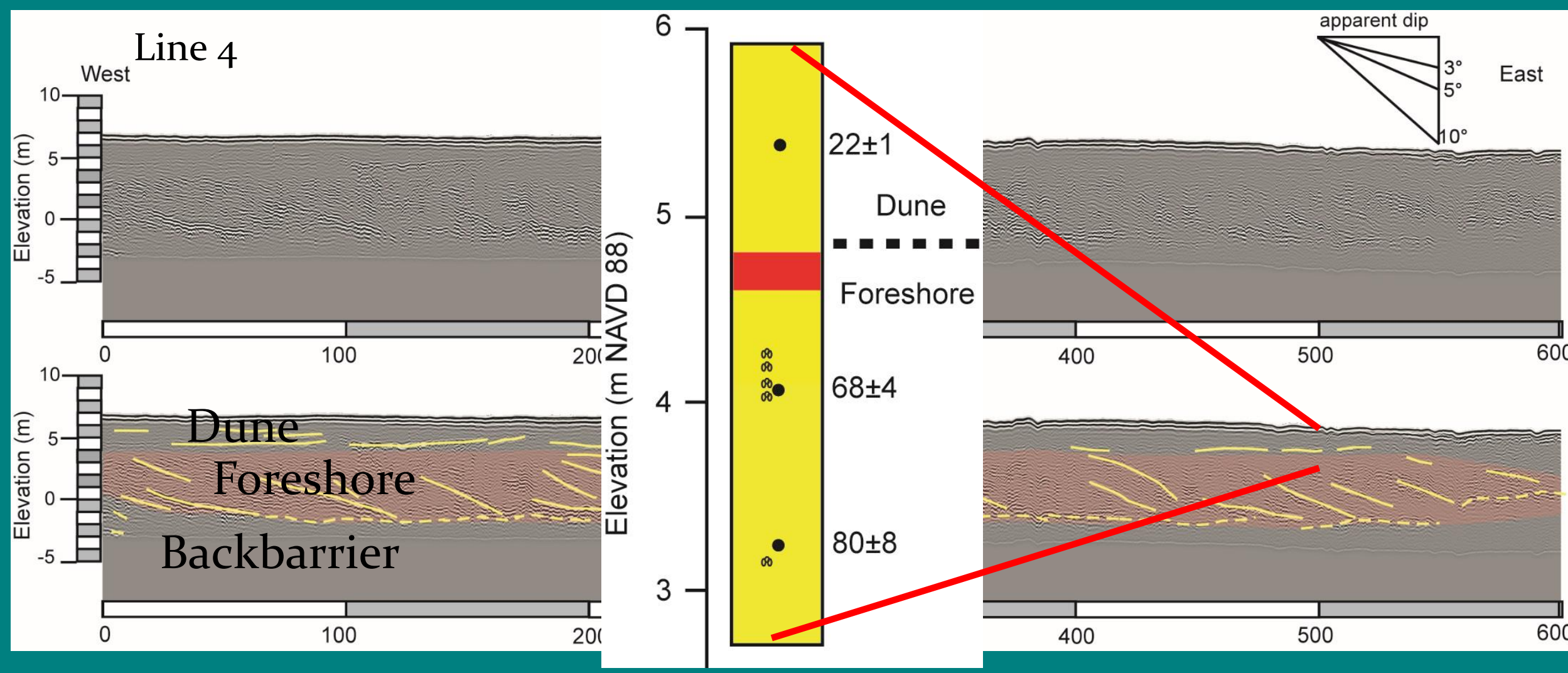


\section{Summary and Conclusion}

Myrtle Beach Barrier:

- Formation of the barrier corresponds to MIS 7

- The backbarrier consists of both MIS 7 and MIS 5a deposites

- The Socastee Formation and the Canepatch Formation at the ICW (cf. Dubar, 1974) is of MIS 5 a and MIS 7 in age, respectively

- MIS 7 RSL is about -2 to $4 \mathrm{~m}$ at NE South Carolina 


\section{Continue...}

North Santee and Hobcaw Barony

- Formed during MIS 5 a as progradational barrier, in agreement with previous studies further south (see Poster by Harris et al. at Booth \#9), but covered by MIS 2 aeolian deposits.

- MSI 5a RSL reached 1 to $6 \mathrm{~m}$ at SE South Carolina

- Youngest Pleistocene coastal deposits are not contemporary along the northeastern South Carolina coast, despite their stratigraphic and geomorphic similarity. 


\section{Acknowledgements}

- The Belle Baruch Foundation

- Jonathan Jones, Richard Lech, Hunter Arrington, and Nicholas Conway(undergraduates) and Ryan Phillip and Joshua Long (graduates) from CCU for field and lab assistance

- University of North Carolina Wilmington for using their PowerProbe 